\title{
A strangulated hernia as a result of ERCP
}

An 83-year-old woman attended for endoscopic retrograde cholangiopancreatography (ERCP) following an episode of acute jaundice. A computed tomography (CT) scan confirmed a dilated common bile duct with a distal filling defect that was later confirmed on magnetic resonance imaging (MRI) to be a biliary stone. She had undergone a right inguinal hernia repair 5 years previously and the CT scan suggested a possible recurrence (๑ Fig. 1).

Sphincterotomy was performed at ERCP and a $10-\mathrm{mm}$ stone was extracted. On the first postoperative day, she developed a temperature of $38.5^{\circ} \mathrm{C}$ and produced a feculent vomit. A plain abdominal radiograph showed distended small-bowel loops. Her arterial blood gases were normal but her white cell count was elevated at $16.2 \times 109 / \mathrm{L}$, as was her C-reactive protein (CRP) at $268 \mathrm{mg} / \mathrm{L}$. A repeat CT scan revealed an incarcerated inguinal hernia causing small-bowel obstruction (๑ Fig. 2).

She underwent an emergency laparotomy, which revealed the strangulated hernia ( Fig.3a) with a segment of necrotic small bowel $270 \mathrm{~cm}$ from the ligament of Treitz ( Fig.3b). This segment was resected using a linear stapler to create a stapled side-to-side anastomosis. The patient recovered well and was fit for discharge 4 days later.

During any endoscopic procedure visualization of the lumen is achieved by the insufflation of gas. However, because ambient "room air" is not well absorbed by the gastrointestinal tract, it must either be suctioned at the end of the procedure or be passed through the gastrointestinal tract as flatus [1]. ERCP can lead to prolonged examination time and overinsufflation [2]. More pertinently it may cause bowel hyperextension limiting the flexibility of the endoscope. It has previously been reported that this may cause barotrauma resulting in perforation or abdominal compartment syndrome [1]. Carbon dioxide is better absorbed by the bowel

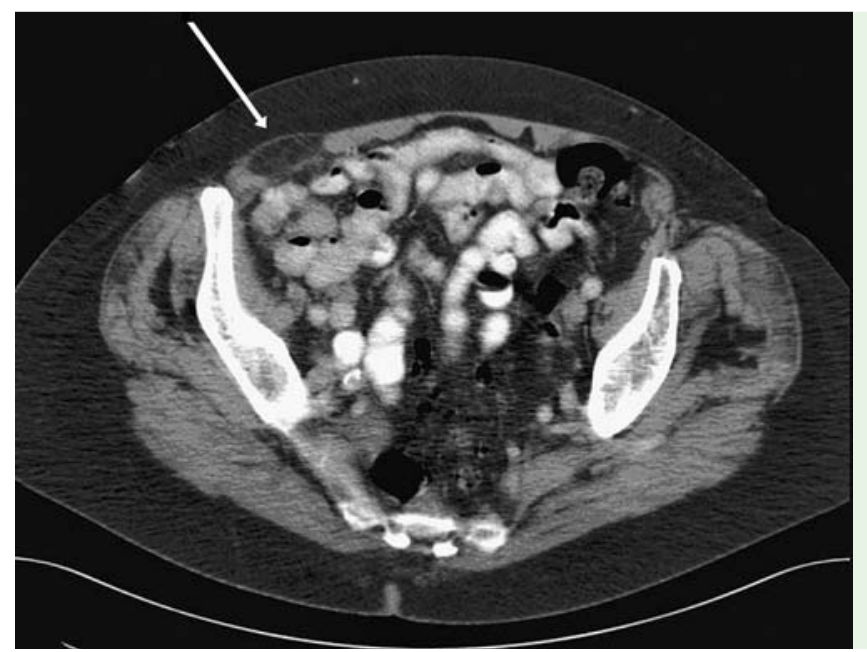

Fig. 1 Image from a computed tomography (CT) scan in an 83-yearold woman who had presented with an acute episode of jaundice showing an incidental finding of a possible recurrent inguinal hernia in the right inguinal region (arrow).

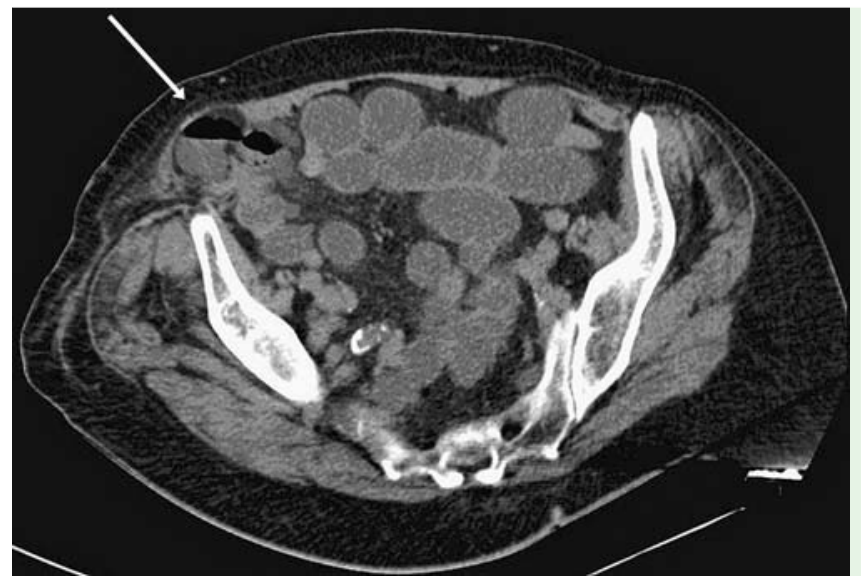

Fig. 2 Image from a computed tomography (CT) scan performed following development of fever and vomiting 1 day after endoscopic retrograde cholangiopancreatography (ERCP) showing an incarcerated inguinal hernia (arrow) with distension of the proximal small bowel and collapse of the distal small bowel.

and has been shown to reduce pain both during and after the procedure, as well as sedation requirements and procedure and recovery times [3].

We suggest that the presence of any abdominal hernias is documented when carrying out a prolonged endoscopic procedure such as an ERCP. Also, in such cases judicious use of room air or carbon dioxide insufflation should be considered to prevent the conversion of an incarcerated to a strangulated hernia as in this case.

Endoscopy_UCTN_Code_CPL_1AK_2AJ

\section{Competing interests: None}

\section{J. Horsnell', V. Pegna', A. Bell²,} A. Mickevicius ${ }^{1}$

${ }^{1}$ Department of Surgery, Weston General Hospital, Weston-Super-Mare, Somerset, UK

2 Department of Gastroenterology, Weston General Hospital, Weston-SuperMare, Somerset, UK 


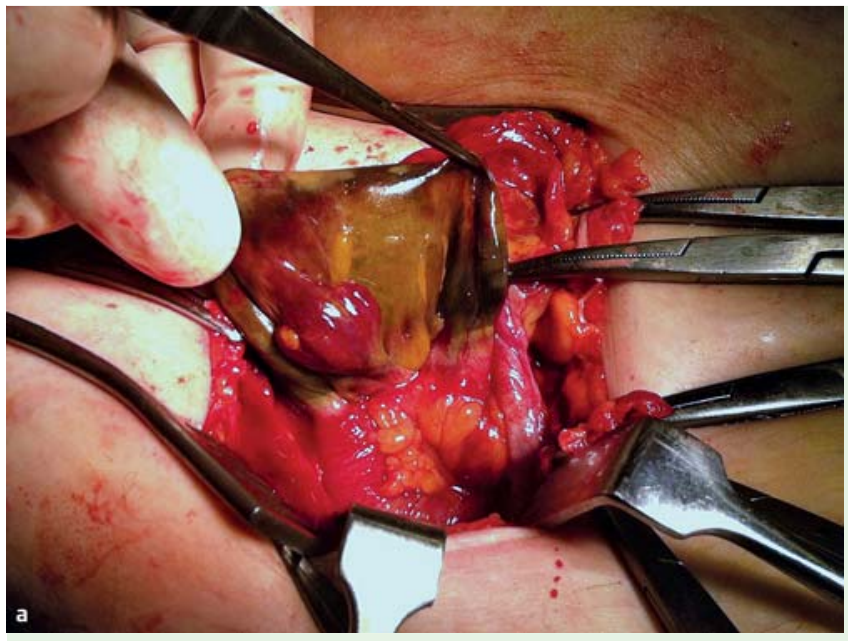

Fig.3 Images during laparotomy showing: a necrotic small bowel at the medial aspect of the previous inguinal hernia repair; b a knuckle of necrotic small bowel following reduction of the strangulated inguinal hernia.

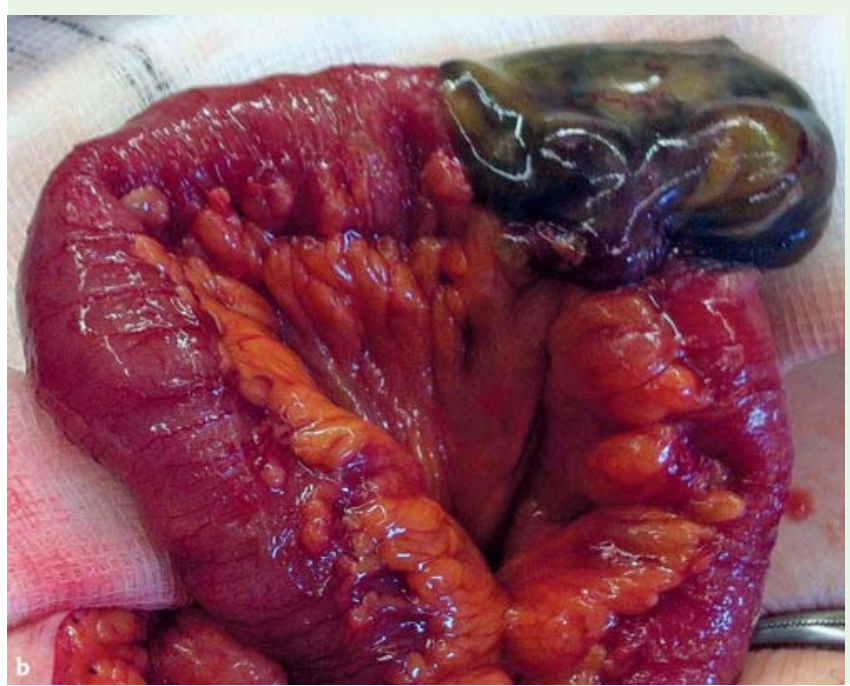

\section{References}

1 Manser CN, Bauerfeind P, Gubler C. Iatrogenic complications in five patients with upper GI bleeding due to ambient air: Case series and literature review. Case Rep Gastroenterol 2012; 6: 197-204

2 Muraki T, Arakura N, Kodama R et al. Comparison of carbon dioxide and air insufflation use by non-expert endoscopists during ERCP. Dig Endosc 2012, DOI: 10.1111/ j.1443-1661.2012.01344.x

3 Dellon E, Hawk J, Grimm I et al. The use of carbon dioxide for insufflation during GI endoscopy: a systematic review. Gastrointest Endosc 2009; 69: 843-849

\section{Bibliography}

DOI http://dx.doi.org/

$10.1055 / \mathrm{s}-0032-1326452$

Endoscopy 2013; 45: E299-E300

(c) Georg Thieme Verlag KG

Stuttgart · New York

ISSN 0013-726X

\section{Corresponding author \\ V. Pegna, MBBS}

Department of General Surgery

Weston General Hospital

Grange Road

Weston-Super-Mare

Somerset

BS23 4TQ

UK

Fax: +44-1934-636366

victoriapegna@hotmail.co.uk 